\title{
Hubungan Gaya Kepemimpinan Transformasional Dan Komunikasi Internal Dengan Kinerja Karyawan Generasi Z Pada Tech Company
}

\author{
Lydia Irena, Effy Zalfiana Rusfian \\ Fakultas Ilmu Komunikasi, Universitas Tarumanagara, Fakultas Ilmu Sosial dan Ilmu Politik, \\ Universitas Indonesia \\ Jl. Letjen S Parman No 1, Jakarta Barat 11440 dan Jl. Prof. DR. Selo Soemardjan, Depok 16424 \\ lydiai@fikom.untar.ac.id, effy_rusf@yahoo.co.id
}

Masuk tanggal : 24-09-2019, revisi tanggal :01-11-2019, diterima untuk diterbitkan tanggal : 03-11-2019

\begin{abstract}
The growth of Generation $Z$ that began to enliven the labor market was noted by Badan Pusat Statistik that as of August 2018 the total Generation $Z$ workforce reached $13.5 \%$ of the total workforce in Indonesia, which in 2020 is predicted to reach $20 \%$. Generation Z who is now starting to color the job market was born in a time when internet technology was in great development, so they have several characteristics that are different from previous generations. The different characteristics between Generation $Z$ and previous generations creates new challenges for companies in managing organizational communication, consists of internal communication. Company or organization have to face this generation who is very virtual and superficial in building a relationship, for communication between employee has a strong correlation with the success of the organization. Besides internal communication, Generation $Z$ employees need leaders who can connect with them and inspire them to big goals. Therefore, study analyzes the relationship between transformational leadership style and internal communication with the employee performance of Generation $Z$ in Tech Company. This research uses quantitative research methods with multiple linear regression analysis. The results of the study finds a significant relationship between transformational leadership style and internal communication with the employee performance of Generation $\mathrm{Z}$ in Tokopedia.
\end{abstract}

Keywords: employee performance, internal communication, organizational communication, transformational leadership style, Tech Company

\begin{abstract}
Abstrak
Pertumbuhan Generasi $\mathrm{Z}$ yang mulai meramaikan pasar tenaga kerja dicatat oleh Badan Pusat Statistik bahwa pada Agustus 2018 total angkatan kerja Generasi Z mencapai 13,5\% dari total angkatan kerja di Indonesia, yang pada 2020 diprediksi mencapai $20 \%$. Generasi $\mathrm{Z}$ yang kini mulai mewarnai pasar kerja lahir pada masa ketika teknologi internet sedang berkembang pesat, sehingga mereka memiliki beberapa karakteristik yang berbeda dari generasi sebelumnya. Perbedaan ciri khas antara Generasi $\mathrm{Z}$ dan generasi sebelumnya menciptakan tantangan baru bagi perusahaan dalam mengelola komunikasi organisasi, yang terdiri dari komunikasi internal. Perusahaan atau organisasi harus menghadapi generasi ini yang sangat virtual dan superfisial dalam membangun hubungan, karena komunikasi antar karyawan memiliki korelasi yang kuat dengan keberhasilan organisasi. Selain komunikasi internal, karyawan Generasi Z membutuhkan pemimpin yang dapat terhubung dengan mereka dan menginspirasi mereka untuk mencapai tujuan besar. Maka
\end{abstract}


dari itu, penelitian ini menganalisis hubungan antara gaya kepemimpinan transformasional dan komunikasi internal dengan kinerja karyawan Generasi Z pada Tech Company. Metode penelitian yang digunakan adalah metode penelitian kuantitatif dengan analisis koefisien korelasi. Hasil penelitian menemukan hubungan yang signifikan antara gaya kepemimpinan transformasional dan komunikasi internal dengan kinerja karyawan Generasi Z di Tokopedia.

Kata Kunci: gaya kepemimpinan transformasional, kinerja karyawan, komunikasi organisasi, komunikasi internal

\section{Pendahuluan}

Generasi Z sekarang telah mulai meramaikan dunia kerja profesional. Badan Pusat Statistik per Agustus 2018 mencatat, bahwa ada sejumlah 4.535.480 angkatan kerja yang berusia 15-19 tahun dan 12.193.700 angkatan kerja yang berumur 20-24 tahun, dimana kedua rentang usia tersebut adalah mereka yang merupakan generasi Z (Stillman dan Stillman, 2017). Terdapat sejumlah 13,5\% dari keseluruhan angkatan kerja di Indonesia yang merupakan generasi Z (Badan Pusat Statistik, 2018) dan angka tersebut akan semakin meningkat kedepannya.

Bencsik dan Machova (2016) menemukan bahwa generasi $\mathrm{Z}$ memiliki ciriciri yang cukup berbeda dengan generasi-generasi sebelumnya. Bahkan millennials yang merupakan angkatan sebelumnya berbeda secara signifikan dengan generasi Z (Stillman dan Stillman, 2017). Generasi ini suka berkolaborasi dalam melakukan pekerjaan (Ferri-Reed, 2010), fleksibel (Renfro, 2012), tanggap terhadap tantangan dan dimotivasi oleh pencapaian (Grafton, 2011), serta suka menelaah cara yang baru dalam menyelesaikan suatu masalah (Wiedmer, 2015).

Perbedaan ini memunculkan tantangan baru bagi praktik manajemen dalam organisasi. Melalui Business 2 Community, Darleen DeRosa (2018) juga mengungkapkan bahwa semakin cepat perusahaan mulai bersiap untuk mengelola generasi $\mathrm{Z}$ maka semakin baik posisi mereka untuk bersaing di pasar tenaga kerja yang semakin kompetitif. Maka dari itu, penting bagi pemimpin organisasi untuk memahami perilaku dan kebiasaan mereka. Setelah memahami perilaku dan kebiasaan generasi Z, diperlukan juga pemahaman akan faktor-faktor yang meningkatkan kinerja mereka. Kinerja karyawan adalah hasil kerja yang dicapai seorang pegawai yang diukur secara kuantitatif dan kualitatif dalam melaksanakannya pekerjaannya sesuai dengan tanggung jawab yang diberikan kepadanya (Robbins, 2006). Knapp, Weber, \& Moellenkamp (2017) mengemukakan empat faktor yang meningkatkan kinerja karyawan generasi Z, yaitu kohesi sosial, berbagi informasi, visi, tujuan, dan tujuan bersama, serta kepercayaan.

Studi yang dilakukan Dell Technologies pada tahun 2018 menemukan bahwa generasi $\mathrm{Z}$ sangat mementingkan interaksi antar manusia. Hubungan adalah hal yang sangat penting bagi mereka (Madden, 2017). Pernyataan ini didukung pula oleh beberapa hasil penelitian terdahulu yang menggagaskan bahwa komunikasi internal yang efektif berperan penting untuk kinerja karyawan (Novitasari \& Setiawan, 2015; Setyoningrum, 2017). Komunikasi internal didefinisikan berdasarkan esensinya oleh Argenti (2003) sebagai penciptaan atmosfir saling 
menghormati di antara seluruh individu didalam organisasi. Sedangkan Bovee dan Thrill (dalam Ragusa, 2010) mengartikan komunikasi internal sebagai pertukaran informasi dan gagasan di dalam organisasi. Komunikasi vertikal dan horizontal yang terjadi di antara karyawan merupakan hal yang integral yang dibutuhkan oleh setiap individu yang bekerja di perusahaan tersebut. Rahmat (2016) mengemukakan bahwa proses kegiatan komunikasi pada sebuah organisasi memiliki peran yang penting selaku katalisator antara karyawan, karyawan dengan supervisor, begitu juga sebaliknya antara supervisor dengan karyawan. Keefektifan dari komunikasi internal memperteguh kepercayaan dari anggota perusahaan bahwa mereka adalah kekayaan yang berharga untuk perusahaan (Argenti, 2010).

Dengan sedemikian rupa pemimpin dengan gaya transformasional pula berhubungan dengan karyawan sehingga menaikkan motivasi mereka. Kepemimpinan transformasional adalah proses dimana para pemimpin dan pengikut saling bekerja sama untuk maju ke tingkat moral dan motivasi yang lebih tinggi. Para pemimpin ini juga membangun hubungan yang membuat karyawan merasa 'terangkat' (Burns, 1978). Gaya kepemimpinan ini membuat karyawan merasa diakui dan dihargai keberadaannya. Selain itu, fokus pemimpin transformasional adalah pada peningkatan komitmen dan usaha karyawan untuk turut berkontribusi dalam mencapai tujuan perusahaan (Leithwood dan Sun, 2012), yang pada akhirnya akan meningkatkan kapasitas kinerja karyawan dan menghasilkan produktivitas yang lebih besar (Leithwood dan Jantzi, 2006).

Melihat perbedaan karakteristik antara generasi $Z$ dengan generasi-generasi terdahulu, pertumbuhan generasi $\mathrm{Z}$ dalam lingkungan kerja, dan ditemukannya hubungan positif antara komunikasi Internal dan kinerja karyawan (Soegiarto, 2016; Nathania, 2014), maka penelitian ini bertujuan untuk menganalisa korelasi antara gaya kepemimpinan transformasional dan komunikasi internal dengan kinerja karyawan generasi $\mathrm{Z}$ di Tech Company Tokopedia.

Tech Company menjadi tempat penarikan sampel karena dilansir oleh Business News Daily studi yang dilakukan Glassdoor bahwa perusahaan yang menempati peringkat teratas sebagai perusahaan yang ingin dimasuki generasi $\mathrm{Z}$ adalah Tech Company (Martins, 2019). Selain itu Tech Company juga memiliki pemimpin-pemimpin yang bertujuan menjadi transformasional dan komunikasi internal yang efektif (Paul, 2017). Khususnya Tech Company Tokopedia memiliki visi, misi, dan tujuan yang erat hubungannya dengan gaya kepemimpinan transformasional inspirational motivation yang menyatakan bahwa atasan mengartikulasikan visi dan tujuan kepada karyawannya.

Hipotesis dari penelitian ini adalah sebagai berikut, (1) H0: Tidak ada hubungan antara gaya kepemimpinan transformasional dan komunikasi internal dengan kinerja karyawan dan generasi Z; (2) H1: Ada hubungan antara gaya kepemimpinan transformasional dan komunikasi internal dengan kinerja karyawan dan generasi $\mathrm{Z}$.

\section{Metode Penelitian}

Peneliti menggunakan paradigma positivistik dalam melaksanakan penelitian ini, dengan mengkaji fenomena pada organisasi yang berkaitan dengan gaya kepemimpinan transformasional, komunikasi internal, dan kinerja karyawan 
secara empiris dan terukur. Untuk mengukur fenomena tersebut, peneliti menggunakan pendekatan kuantitatif, dimana korelasi antara gaya kepemimpinan transformasional dan komunikasi internal dengan kinerja karyawan generasi $\mathrm{Z}$ di Tech Company dikuantifikasi. Desain penelitian ditentukan dengan tiga perspektif yaitu cross-sectional, retrospective study, dan non-eksperimental. Pendekatan kuantitatif non-eksperimental ini menggunakan kuesioner yang dijadikan sebagai data primer dan tinjauan literatur sebagai data sekunder.

Populasi dari penelitian ini adalah seluruh karyawan Generasi $\mathrm{Z}$ dengan kriteria responden yaitu, generasi $Z$ yang telah bekerja selama sedikitnya tiga bulan sebagai karyawan pada Tech Company Tokopedia. Kriteria berupa minimal tiga bulan lama bekerja ditentukan karena menurut BrightHR (2019) pada masa percobaan kerja tersebut terdapat komunikasi yang intensif antara atasan dan karyawan, sehingga karyawan dapat menilai gaya kepemimpinan atasannya serta komunikasi internal perusahaan. Kriteria lainnya juga ditentukan sejalan dengan sasaran dari penelitian ini.

Dalam penelitian ini, penarikan sampel menggunakan teknik nonprobability sampling, yaitu snowball, dimana peneliti mendapatkan referensi tempat penarikan sampel dari salah satu karyawan Tokopedia yang mereferensikan tempatnya bekerja, karena di perusahaan tersebut terdapat banyak karyawan generasi $\mathrm{Z}$ atau yang lahir pada tahun $1995 \mathrm{ke}$ atas.

Teknik analisis data dalam penelitian ini menggunakan beberapa uji statistik yang dimulai dari analisis deskriptif, uji validitas, uji reliabilitas, uji asumsi, hingga analisis koefisien korelasi. Analisis statistik ini dilakukan terhadap data yang didapat dari hasil penyebaran kuesioner. Dalam penelitian ini, peneliti memakai program SPSS for Mac sebagai alat pengolahan data dan juga untuk melakukan pengujian analisis data.

\section{Hasil Penemuan dan Diskusi}

Penelitian dilakukan dengan terlebih dahulu dilaksanakan pre-test untuk memastikan bahwa alat ukur teruji validitas dan reliabilitasnya. Kemudian setelah itu barulah peneliti melakukan penelitian sesungguhnya dengan menyebarkan kuesioner kepada responden di Tokopedia dan ketika kuesioner dikembalikan peneliti mulai melakukan analisis koefisien korelasi terhadap data yang diperoleh terkait variabel komunikasi internal, gaya kepemimpinan transformasional, dan kinerja karyawan Generasi Z.

Pre-test terhadap 20 orang responden pada awalnya dilaksanakan untuk menguji validitas dan reliabilitas dari kuesioner. Setelah melakukan pre-test sebanyak dua kali akhirnya didapatkan bahwa alat ukur memiliki tingkat reliabilitas yang lebih tinggi, dimana nilai Cronbach's Alpha $>0,60$, yaitu 0,978. Hasil uji validitas juga menunjukkan bahwa semua butir pernyataan valid karena memiliki $r$ hitung > r tabel. Selanjutnya, peneliti melaksanakan pengumpulan data di Tokopedia dengan jumlah responden sebanyak 20 orang. Berikut pada Tabel 1 adalah hasil analisis koefisien korelasi. 
Tabel 1. Hasil Analisis Koefisien Korelasi

\section{Correlations}

\begin{tabular}{|c|c|c|c|c|}
\hline & & $\begin{array}{c}\text { Gaya_Kepem } \\
\text { impinan_Tra } \\
\text { nsformasiona } \\
\text { I }\end{array}$ & $\begin{array}{c}\text { Komunikasi_I } \\
\text { nternal }\end{array}$ & $\begin{array}{c}\text { Kinerja_Kary } \\
\text { awan }\end{array}$ \\
\hline \multirow{3}{*}{$\begin{array}{l}\text { Gaya_Kepemimpi } \\
\text { nan_Transformas } \\
\text { ional }\end{array}$} & $\begin{array}{l}\text { Pearson } \\
\text { Correlation }\end{array}$ & 1 & $.819^{* * *}$ & $.784^{* * *}$ \\
\hline & Sig. (2-tailed) & & .000 & .000 \\
\hline & $\mathrm{N}$ & 20 & 20 & 20 \\
\hline \multirow[t]{3}{*}{$\begin{array}{l}\text { Komunikasi_Inter } \\
\text { nal }\end{array}$} & $\begin{array}{l}\text { Pearson } \\
\text { Correlation }\end{array}$ & $.819^{* * *}$ & 1 & $.581^{* *}$ \\
\hline & Sig. (2-tailed) & .000 & & .007 \\
\hline & $\mathrm{N}$ & 20 & 20 & 20 \\
\hline \multirow[t]{3}{*}{$\begin{array}{l}\text { Kinerja_Karyawa } \\
\mathrm{n}\end{array}$} & $\begin{array}{l}\text { Pearson } \\
\text { Correlation }\end{array}$ & $.784^{* * *}$ & $.581^{* * *}$ & 1 \\
\hline & Sig. (2-tailed) & .000 & .007 & \\
\hline & $\mathrm{N}$ & 20 & 20 & 20 \\
\hline
\end{tabular}

$* *$. Correlation is significant at the 0.01 level (2-tailed).

Hasil analisis koefisien korelasi menampilkan hubungan yang positif dan signifikan antara gaya kepemimpinan transformasional dan komunikasi internal dengan kinerja karyawan generasi $\mathrm{Z}$ di Tokopedia. Pemimpin dengan gaya transformasional memberikan teladan etis dalam perbuatannya, memperoleh kepercayaan dan rasa hormat dari karyawannya, menumbuhkan kebanggaan, serta mengartikulasikan sebuah visi yang menarik dan menginspirasi karyawannya. Seperti apa yang juga dikemukakan oleh Krogsgaard, Thomsen, \& Andersen (2014) bahwa pemimpin perlu menyampaikan visi organisasi secara jelas kepada karyawan. Pemimpin memfokuskan tindakan atau usaha dan kemudian mengekspresikan tujuan organisasi dengan cara-cara yang sederhana dengan menggunakan berbagai penanda. Pemimpin pula membangkitkan semangat kerja sama dalam tim, antusiasme dan optimisme pada pekerja generasi Z. Hasil penelitian inipun mendukung apa yang dinyatakan oleh Claire Madden (2017) dalam bukunya yaitu Hello Gen Z, bahwa gaya kepemimpinan transformasional sangat dibutuhkan oleh generasi Z. Karyawan generasi Z membutuhkan pemimpin yang dapat terhubung dengan mereka dan menginspirasi mereka menuju tujuan yang besar.

Selaras dengan apa yang dituliskan oleh Cutlip, et al. (2006) bahwa komunikasi internal menjadi penting karena melalui itu pemimpin dapat menyampaikan apa yang menjadi hal prinsipil dari organisasi, seperti pernyataan visi, pernyataan misi, dokumen kebijakan, dan materi pelatihan. Pengungkapan visi menjelaskan tujuan strategis dan pencapaian di masa yang akan datang dari sebuah perusahaan sehingga setiap karyawan berada dihalaman yang sama dengan pandangan ke arah yang sama juga. Selanjutnya adalah pernyataan misi yang lebih spesifik dan operasional, dimana hal ini mengarahkan karyawan dalam menentukan tujuan dan prioritas sehingga semua karyawan memiliki komitmen tinggi untuk mencapai misi organisasi. Berbagai peraturan baik dari kebijakan perusahaan atau pemerintahan berupa prosedur ataupun kode etik juga tergabung dalam dokumen 
kebijakan suatu perusahaan, hingga materi pelatihan dimana setiap karyawan mengalami sosialisasi dan enkulturasi.

Salah satu proses yang penting dalam setiap organisasi adalah kepemimpinan, sebab kepemimpinan menentukan keberhasilan sebuah organisasi. Pace dan Faules (1998) mengatakan bahwa kepemimpinan dinyatakan dengan gaya kerja atau cara bekerja yang tetap atau konsisten, dimana kepemimpinan memiliki tujuan untuk membantu individu menjaga motivasinya, bahkan meningkatkan motivasi mereka. Gaya kerja tersebut meliputi semua yang diucapkan dan diperbuat kepada karyawan lain, sehingga konsep ini menunjukkan bahwa ada kombinasi antara bahasa dan tindakan yang menjadi sebuah pola konsisten. Diantara berbagai gaya kepemimpinan, diidentifikasikan bahwa generasi $\mathrm{Z}$ cenderung merespon lebih baik kepada gaya kepemimpinan transformasional (Green, 2018).

Karyawan ggillesenerasi $\mathrm{Z}$ membutuhkan pemimpin yang dapat terhubung dengan mereka dan menginspirasi mereka menuju tujuan yang besar (Madden, 2017). Generasi $Z$ mencari pemimpin yang memberikan teladan yang layak ditiru melalui apa yang mereka lakukan, serta memiliki fokus untuk memberdayakan dan mendukung orang lain untuk memenuhi potensi mereka. Penemuan ini pula sejalan dengan penelitian yang dilakukan oleh Soegiarto (2016), Gillespie \& Mann (2000), Cavazotte (2013), dan Walumbwa \& Hartnell (2011) bahwa gaya kepemimpinan transformasional memiliki pengaruh yang positif dan signifikan terhadap kinerja karyawan.

Generasi Z yang meskipun dikatakan memiliki hubungan superfisial dan virtual (Bencsik dan Machova, 2016), ternyata ditemukan dalam penelitian ini bahwa kinerja mereka di perusahaan sangat dipengaruhi oleh komunikasi internal. Hal ini juga sejalan dengan studi yang dilakukan oleh Dell Technologies (2018) dan Madden (2017) bahwa generasi Z sangat mementingkan interaksi antar manusia dan hubungan adalah hal yang sangat penting bagi mereka. Penemuan ini pula sejalan dengan penelitian sebelumnya yang menemukan kalau komunikasi internal mempunyai korelasi yang positif dengan kinerja karyawan (Levi \& Slem, 1995; Lestari, 2015; Novitasari \& Setiawan, 2015; Setyoningrum \& Suminar, 2017).

Selanjutnya hasil penelitian ini menyokong apa yang menjadi penemuan Nathania (2014) bahwa komunikasi vertikal, komunikasi horizontal, dan komunikasi lintas-saluran memiliki hubungan positif dengan kinerja karyawan. Komunikasi internal berfungsi untuk menyampaikan penghargaan kepada seluruh individu di organisasi dengan cara menerima dan mendengar informasi dan ide yang mereka kemukakan (The Community Tool Box, Promoting Internal Communication, 2012). Generasi Z yang suka berinovasi (Wiedmer, 2015) tentunya akan semakin meningkat kinerjanya jika komunikasi internal dalam perusahaan tempat ia bekerja berjalan dengan efektif. Pada akhirnya, penelitian yang dilakukan saat ini juga mendukung penelitian sebelumnya yang telah dilakukan oleh Sari \& Aryanto (2014), Atika, Fristin \& Suwandaru (2017), dan Muttaqin (2017) bahwa gaya kepemimpinan transformasional dan komunikasi internal memiliki korelasi dengan kinerja karyawan.

\section{Simpulan}


Ditemukan hubungan yang positif dan signifikan antara gaya kepemimpinan transformasional dan komunikasi internal dengan kinerja karyawan generasi $\mathrm{Z}$ di Tokopedia. Diantara kedua variabel independen tersebut, gaya kepemimpinan transformasional mempunyai korelasi yang lebih signifikan dengan kinerja karyawan dibandingkan komunikasi internal. Hasil ini mendukung penelitian sebelumnya yang dilaksanakan oleh Atika, Fristin \& Suwandaru (2017), Mellisa Soegiarto (2016), dan Nathania (2014) kalau gaya kepemimpinan transformasional dan komunikasi internal mempunyai hubungan dengan kinerja karyawan.

Pemimpin perusahaan dapat menerapkan gaya kepemimpinan transformasional yaitu, dengan memberikan teladan etis dalam perbuatannya, memperoleh kepercayaan dan rasa hormat dari karyawannya, menumbuhkan kebanggaan, serta mengartikulasikan sebuah visi yang menarik dan menginspirasi karyawannya. Pihak manajemen perusahaan juga dapat memaksimalkan komunikasi internal, terutama pada komunikasi vertikal dan komunikasi horizontal yaitu dengan memastikan bahwa setiap informasi tersampaikan dengan tepat dan lancar, baik dari supervisor ke karyawan, sebaliknya, maupun antara sesama karyawan. Selain itu juga memastikan bahwa sesama karyawan dapat berdiskusi dan mendukung satu sama lain.

Melihat bahwa mayoritas responden memiliki pendidikan S1 yaitu sebesar $81 \%$ dan tingkat kinerja karyawan berada pada klasifikasi yang sangat tinggi secara rata-rata, kedepannya perusahaan dapat mempekerjakan setidaknya mereka yang memiliki pendidikan tersebut agar kinerja perusahaan menjadi tinggi. Hasil penelitian ini seyogyanya dapat memicu dan mendorong terlaksananya penelitianpenelitian selanjutnya di bidang komunikasi organisasi dan kepemimpinan dengan mengaplikasikan berbagai variabel lain yang belum diukur pada penelitian ini seperti pelatihan kerja, kemampuan kerja, employee engagement, efektivitas tim, self-efficacy, dan motivasi kerja seperti yang ditemukan pada sejumlah penelitian terdahulu sehingga dapat ditemukan aspek-aspek lain yang dominan hubungannya terhadap kinerja karyawan. Penelitian selanjutnya dapat berfokus pada 1 Tech Company atau 1 organisasi saja dan meningkatkan jumlah responden seiring dengan semakin banyaknya Generasi $\mathrm{Z}$ yang memasuki dunia kerja, sehingga objek studi menjadi lebih terfokus dan tidak terdapat beragam konteks yang bercampur.

\section{Ucapan Terima Kasih}

Peneliti menyampaikan terima kasih kepada sejumlah karyawan Tokopedia yang sudah bersedia menjadi responden dan Universitas Tarumanagara yang telah mendukung dengan memberikan bantuan dana demi terlaksananya penelitian.

\section{Daftar Pustaka}

Argenti, P. A. (2003). Corporate Communication. New York: McGraw-Hill/Irwin. Argenti, P. A. (2010). Corporate Communication. Jakarta: Salemba Humanika. 
Atika, Fristin, \& Suwandaru. 2017. Pengaruh Kepemimpinan Transformasional dan Komunikasi Terhadap Kinerja Karyawan (Pada PT. PLN (PERSERO) Area Malang Rayon Malang Kota). Jurnal Bisnis dan Manajemen. 4(1).

Badan Pusat Statistik. (2018). Penduduk Berumur 15 Tahun ke atas Menurut Golongan Umur dan Kegiatan. https://www.bps.go.id/statictable/2016/04/04/1904/penduduk-berumur-15tahun-ke-atas-menurut-golongan-umur-dan-jenis-kegiatan-selamaseminggu-yang-lalu-2008---2018.html

Bencsik, A., \& Machova, R. (2016). Knowledge Sharing Problems from the Viewpoint of Intergeneration Management. In ICMLG2016 - 4th International Conference on Management, Leadership and Governance: ICMLG2016. Academic Conferences and Publishing Limited.

BrightHR. (2019). https://www.brighthr.com/articles/hiring/probation-periods/theimportance-of-employee-probation-periods

Burns J. M. (1978). Leadership. New York: Harper \& Row.

Cavazotte, F., Moreno, V., \& Bernardo, J. (2013). Transformational Leaders and Work Performance: The Mediating Roles of Identification and Selfefficacy. BAR - Brazilian Administration Review, 10.

Cutlip, Scott M., et al. (2006). Effective Public Relations. Jakarta: Prenada Media Group.

Green, Daryl. (2018). https://medium.com/@drdarylgreen/inspiring-generation-zwith-transformational-leadership-8a356cb3081c

Dell Technologies. (2018). https://www.delltechnologies.com/enus/perspectives/gen-z.htm

DeRosa, Darleen (2018). https://www.business2community.com/leadership/4best-tips-for-successful-leadership-of-generation-z-employees-02139823.

Ferri-Reed, J. (2010). The keys to engaging millennials. The Journal for Quality and Participation, 33(1).

Gillespie, N.A. and Mann, L. ( $\square$ 2000). The building- blocks of trust: the role of transformational leadership and shared values in predicting team members' trust in their leaders'. Tesis: University of Melbourne.

Grafton, Melissa (2011). Growing a business and becoming more entrepreneurial: The five traits of success. Strategic Decision, 27(6).

Knapp, Curtis A., Weber, Christine, \& Moellenkamp, S. (2017). Challenges and strategies for incorporating Generation $\mathrm{Z}$ into the workplace. Corporate Real Estate Journal, 7(2).

Krogsgaard, J. A., Thomsen, P., \& Andersen, L. B. (2014). Only If We Agree? How Value Conflicts Moderate the Relationship Between Transformational Leadership and Public Service Motivation. International Journal of Public Administration, 37(12).

Leithwood, K. A., \& Sun, J. (2012). The Nature and Effects of Transformational School Leadership: A Meta-Analytic Review of Unpublished Research. Educational Administration Quarterly, 48.

Leithwood, K. A., \& Jantzi, D. (2006). Transformational School Leadership for Large-Scale Reform: Effects on Students, Teachers, and Their Classroom Practices. School Effectiveness and School Improvement, 17. 
Lestari, Evi Dyah. (2015). Analisis Pengaruh Beban Kerja dan Konflik PekerjaanKeluarga terhadap Kinerja Karyawan dengan Stress sebagai Variabel Mediasi (Studi pada Personal Banking Officer PT. Bank Negara Indonesia (Persero) Tbk Kantor Wilayah Semarang). Tesis: Universitas Diponegoro.

Levi, D., \& Slem, C. (1995). Team work in research and development organizations: The characteristics of successful teams. International Journal of Industrial Ergonomics, 16(1).

Madden, Claire. (2017). Hello Gen Z: Engaging the Generation of PostMillennials. Australia: Hello Clarity.

Martins. (2019). https://www.glassdoor.com/research/studies/gen-z-workers/

Muttaqin, M. F. F. (2017). Pengaruh Kepemimpinan Transformasional dan Komunikasi Interpersonal Terhadap Kinerja Karyawan di Divisi Penyelamatan dan Penyelesaian Kredit Bank BJB dengan Komitmen sebagai Variabel Intervening. Tesis: Universitas Pasundan University.

Nathania. (2014). Hubungan Aliran Komunikasi Organisasi Dengan Kinerja Karyawan Di PT. Sarana Lubitama Semesta. Jurnal E-Komunikasi, 2(3).

Novitasari, Devi., \& Setiawan, Rony Ika. (2015). Pengaruh Komunikasi Internal, Pelatihan Kerja dan Kemampuan Kerja terhadap Kinerja Karyawan pada CV. Tirto Agung Lodoyo. Riset Mahasiswa Ekonomi (RITMIK), 2(1).

Paul. (2017). Tech Company juga memiliki pemimpin-pemimpin yang bertujuan menjadi transformasional. https://blog.taskpigeon.co/leadership-strategy/

Ragusa, A. (2010). Internal communication management: individual and organizational outcomes. Italia: Ventus.

Rahmat, Abdul \& Kadir, Syaiful (2016). Manajemen Kepemimpinan Dan Kemampuan Berkomunikasi Kepala Sekolah Pada Kinerja Pendidik. Jurnal Komunikasi, $8(1)$. https://journal.untar.ac.id/index.php/komunikasi/article/view/43

Renfro, A. (2012). Meet generation Z. http://gettingsmart.com/2012/12/meetgeneration-z/

Robbins, S. P. (2006). Perilaku Organisasi (10th Ed). Jakarta: PT. Indeks Kelompok Gramedia.

Sari, D. N., Aryanto, R. (2014). Analisis Pengaruh Kepemimpinan Transformasional dan Komunikasi Internal Terhadap Motivasi Kerja dan Dampaknya Pada Kinerja Karyawan di Kantor PT. Waskita Karya Divisi Gedung. Tesis: Universitas Binus University.

Setyoningrum, Rini. (2016). Pengaruh Komunikasi Internal terhadap Etos Kerja Pegawai di Pusat Pengembangan Pendidikan Anak Usia Dini dan Pendidikan Masyarakat (PP-PAUD dan Dikmas) Jawa Tengah. Journal of Nonformal Education and Community Empowerment, 1(1).

Soegiarto, Melissa. (2016). Pengaruh Kepemimpinan Transformasional Terhadap Kinerja Karyawan Divisi Penjualan dan Pemasaran di CV. Norton Surabaya. AGORA, 4(2).

Stillman, D., \& Stillman, J. (2017). Gen Z @ Work. New York: HarperBusiness.

Walumbwa, F.O. \& Hartnell, C. (2011). Transformational leadership and organizational culture: Toward integrating a multilevel framework. Handbook of organizational culture and climate. 
Vol. 11, No. 2, Desember 2019, Hal 223 - 232

Wiedmer, T. (2015). Generations do differ: Best practices in leading traditionalists, boomers, and generations $\mathrm{X}, \mathrm{Y}$, and $\mathrm{Z}$, delta kappa gamma bulletin. International Journal of Professional Educators, 82(1), 51-59. 